\title{
Differential Diagnostic Value of Bilateral Inferior Petrosal Sinus Sampling (BIPSS) in ACTH-Dependent Cushing Syndrome: a Systematic Review and Meta-Analysis
}

\section{Hao Wang ( $\nabla$ wanghaodl@126.com )}

First Affiliated Hospital of Dalian Medical University https://orcid.org/0000-0002-0795-2181

\section{Ying Ba}

First Affiliated Hospital of Dalian Medical University

\section{Qian Xing}

First Affiliated Hospital of Dalian Medical University

\section{Run-Ce Cai}

First Affiliated Hospital of Dalian Medical University

\section{Research article}

Keywords: Bilateral inferior petrosal sinus sampling, ACTH-dependent Cushing syndrome, Differential diagnosis , Diagnostic meta-analysis

Posted Date: August 20th, 2020

DOI: https://doi.org/10.21203/rs.2.21469/v3

License: (c) (i) This work is licensed under a Creative Commons Attribution 4.0 International License. Read Full License

Version of Record: A version of this preprint was published on September 17th, 2020. See the published version at https://doi.org/10.1186/s12902-020-00623-3. 


\section{Abstract}

Background: Previous studies have shown inconsistent results about the usefulness of bilateral inferior petrosal sinus sampling (BIPSS) in differential diagnosis of adrenocorticotropic hormone (ACTH)-dependent Cushing syndrome. This meta-analysis evaluated the diagnostic value of BIPSS via the published literature.

Methods: This study searched PubMed, Embase, Web of Science, Cochrane library, and Wanfang database for published data on the use of BIPSS in Cushing syndrome differential diagnosis as of October 2019. Sensitivity, specificity, positive likelihood ratio (PLR), negative likelihood ratio (NLR), diagnostic odds ratio (DOR), and receiver operating characteristic (ROC) curves were calculated based on the relevant data.

Results: This meta-analysis included a total of 23 studies with 1,617 patients. The calculated sensitivity, specificity, PLR, and NLR were 0.94 (95\% confidence interval, Cl: 0.91-0.96), 0.89 (95\% Cl: 0.79-0.95), 8.8 (95\% Cl: $4.3-17.9$ ), and 0.07 (95\% Cl: $0.04-0.11)$, respectively. The pooled DOR and area under the ROC curve were 129 (95\% Cl: 48-345) and 0.97 (95\% Cl: 0.95-0.98), respectively.

Conclusion: This meta-analysis indicated that BIPSS had high diagnostic value for detecting ACTH in patients with ACTH-dependent Cushing syndrome, and BIPSS should be used as an effective method to identify ACTHsecretion sources.

\section{Background}

Adrenocorticotropic hormone (ACTH)-dependent Cushing syndrome(CS) is caused by excessive secretion of ACTH by the pituitary or pituitary tumors, causing bilateral adrenal hyperplasia and excessive cortisol secretion with clinical manifestations such as a moon-shaped face, buffalo hump, and hypertension. The majority of ACTHdependent Cushing syndrome cases are caused by Cushing disease (CD), a condition in which ACTH-secreting tumors are responsible for elevated ACTH levels. Other cases, such as ectopic ACTH syndrome (EAS), have ectopic sources. These have different therapeutic principles and prognoses. Based only on clinical manifestations, detection of cortisol levels and ACTH, high- and low-dose dexamethasone suppression tests, and imaging, these conditions are not completely distinguishable. Studies have shown that non-functional pituitary tumors are common [1-3], suggesting that even if a pituitary tumor is revealed by magnetic resonance imaging (MRI), the tumor is not necessarily the source of the ACTH. Some ACTH-secreting tumors are small in size, and may not be revealed by MRI. Only $50-70 \%$ of these tumors are diagnosed $[4,5]$. Therefore, negative MRI does not completely exclude ACTH-secreting tumors. In high-dose dexamethasone suppression test (HDDST), most ACTHsecreting tumors are suppressed, while most EASs are unrepressed. However, a small number of patients have unpredicted presentations on HDDST [6, 7]. An HDDST cannot effectively distinguish between ACTH-secreting tumors and EAS. Therefore, the localization rate of ACTH-secreting tumors is very low. In addition to the positive rate of MRI detection mentioned above, the HDDST has approximately $78-81 \%$ sensitivity and $67-81 \%$ specificity $[8,9]$, while the corticotrophin-releasing hormone(CRH) stimulation test has $76-91 \%$ sensitivity and $95 \%$ specificity $[10,11]$. For these reasons, more effective diagnostic approaches are needed to distinguish the two diseases.

Bilateral inferior petrosal sinus sampling (BIPSS) has been considered to be the gold standard for differential diagnosis of the above two diseases. BIPSS is an interventional method in which a blood sample from the bilateral inferior petrosal sinus and a peripheral blood sample are used to measure ACTH by calculating the lower 
sinus/peripheral (IPS/P) ACTH ratio and left and right inferior petrosal sinus (IPS/IPS) ACTH ratio. The IPS/P ACTH ratio is used to distinguish between CD and EAS. In general, an IPS/P ACTH ratio of $\geq 2$ before a CRH stimulation test and an IPS/P ACTH ratio of $\geq 3$ after the $\mathrm{CRH}$ test are criteria for diagnosing CD [6]. These diagnostic criteria are also recommended by other centers[12,13].The ratio of ACTH between the left and right IPS is used to determine the location of pituitary microadenomas, with IPS/IPS $>1.4$ indicating a tumor located at the side with higher ACTH, and IPS/IPS $\leq 1.4$ indicating a tumor locating near the midline[6]. Studies have shown that vasopressin receptor is present on the surface of ACTH-secreting tumors, and administration of vasopressin stimulates the release of ACTH [14]. Application of desmopressin (DDAVP) during BIPSS enhances diagnostic accuracy [15]. Generally speaking, although BIPSS is a mildly invasive examination, it is relatively safe. It has occasional complications, including groin hematoma, cerebral hemorrhage, and vasovagal reactions (VVRs) $[12,16,17]$. The incidence of groin hematoma is approximately $4 \%$, and the incidences of cerebral hemorrhage and vasovagal reactions (VVRs) are below 1\%. Occasional pulmonary embolism is also reported by some researchers. However, meta-analysis of BIPSS is currently unavailable. This study performed a meta-analysis of BIPSS for the differential diagnosis of ACTH-dependent Cushing syndrome and evaluated the differential diagnostic value for this condition.

\section{Methods}

\section{Data Sources, Search Strategy, and Selection Criteria}

This study strictly followed the Preferred Reporting Items for Systematic reviews and Meta- Analyses (PRISMA) guidelines [18] and used PubMed, Embase, Web of Science, Cochrane Library, and Wanfang databases to search for studies using BIPSS for the differential diagnosis of ACTH-dependent Cushing syndrome as of October 2019. The following search terms were used: petrosal sinus sampling, bilateral inferior petrosal sinus sampling, Cushing's syndrome, Cushing disease, and ectopic Cushing syndrome. The search strategies in the various databases were as follows: PubMed: ("petrosal sinus sampling" [Mesh]) AND "Cushing's syndrome" [Mesh]); Embase: (Emtree term-exploded = Cushing's syndrome AND Abstract=petrosal sinus sampling); Web of Science: TS = (petrosal sinus sampling AND Cushing's syndrome); and Cochrane Library and WanFang: keyword = (petrosal sinus sampling AND Cushing's syndrome). During searching, keywords and free words were used simultaneously. Manual searches were also used, and relevant references included in the extracted papers were also searched.

Literature was searched by two of the authors(Hao Wang, Run Ce-Cai) independently. If there was a disagreement for inclusion or exclusion, another author(Ying $\mathrm{Ba}$ ) became involved in the resolution following discussion. The inclusion criteria of this meta-analysis were as follows: (1) patients confirmed with Cushing syndrome (CS) and unclear ACTH source; (2) CS caused by ACTH-secreting tumor or EAS confirmed by postoperative pathology or by clinical manifestations, biochemical tests, and surgery; (3) the study provided true positives (TP), false positives (FP), false negatives (FN), and true negatives (TN) or the data for the calculation of TP, FP, FN, and TN. The exclusion criteria were: (1) studies with incomplete data or data which could not be used to calculate the contingency table, (2) non-original studies, (3) repeated studies, (4) animal studies, and (5) studies with less than 20 patients included.

\section{Data Collection and Quality Assessment}


Two authors(Qian Xing, Ying Ba) read the included papers and extracted relevant data through discussion. In case of disagreement, another author(Hao Wang) was involved in further discussion. Contents of data extraction in the literature included: name of the first author, year of publication, country of the study, study design (prospective and retrospective), the application of CRH or DDAVP stimulation, the application of prolactin (PRL) correction, TP, FP, FN, and TN. The quality of the included studies was evaluated by two of the authors independently using the Quality Assessment of Diagnostic Accuracy Studies (QUADAS-2) $[19,20]$ according to the four aspects as follows: selection of cases, trials to be assessed, gold standard, and flowchart and progress of cases. Each of the assessments contained seven items which were answered as "yes," "no," or "uncertain." An answer of "yes" indicated that the risk offset of the study was low, while the answers of "no" and "uncertainty" indicated high risk offset.

\section{Statistical Analysis}

This study used Revman 5.3 for quality evaluation and Stata 14.0 statistical software for data analysis. The TP, FP, FN, TN, sensitivity, specificity, positive likelihood ratio (PLR), negative likelihood ratio (NLR), and corresponding 95\% confidence intervals (Cls) of each included study were extracted, otherwise, we calculated the integrated sensitivity, specificity, PLR, and NLR using the bivariate random effects model [21]. The receiver operating characteristic (SROC) curve and the area under the ROC curve were calculated using a hierarchical regression model [22]. The Q statistic and I-square were used for heterogeneity tests. P $>0.10$ indicated no significant heterogeneity, while $P<0.10$ indicated significant heterogeneity for the Q statistic [23, 24]. The fixed effect model was used when the heterogeneity was low $(P>0.05$, I-square $<50 \%)$, while the random effect model was used when the heterogeneity was high $(P<0.05$, l-square $>50 \%)$. A meta-regression analysis of the diagnostic odds ratio (DOR) was performed according to the study design, year of publication, country of publication, application of $\mathrm{CRH}$ or DDAVP, application of PRL correction, and the number of patients included in the study[25]. Deek's asymmetry test was used to evaluate whether a publication bias existed[26]. All reported $\mathrm{P}$ values were two-sided, and $\mathrm{P}<0.05$ was considered statistically significant for pooled diagnostic parameters.

\section{Results}

As shown in Figure 1 which describes the literature searches and the workflow for study inclusion, there were 822 articles in the initial search, but 256 of them were found to be duplicated and were removed from further analysis. In addition, a total of 472 articles included irrelevant research articles, reviews, commentaries, editorials, and letters, which were further removed. Of the remaining 94 articles, those that contained incomplete data, replicated research, no gold standard, incomplete research descriptions, or less than 20 patients were also removed. Thus, a total of 23 studies were included in this meta-analysis [3,6, 12,13, 27-45].

Table 1 shows the characteristics of the included studies which were published in 1991-2019, including 11 studies conducted in Europe, nine studies conducted in the United States or Brazil, and 3 studies conducted in China or India. There were 3 prospective studies and 20 retrospective studies included in this meta-analysis. Figure 2 shows the quality of the included studies.

The summary results for sensitivity and specificity are presented in Figure 3 . The pooled sensitivity was 0.94 (95\% Cl: 0.91-0.96), the specificity was 0.89 (95\% Cl: 0.79-0.95), the PLR was 8.8 (95\% Cl: 4.3-17.9), and the NLR was 0.07 (95\% Cl: 0.04-0.11). The DOR of further integration of BIPSS on ACTH-dependent Cushing syndrome was 129 (95\% Cl: 48-345; Figure 4). Lastly, the summary area under the ROC curve was 0.97 (95\% Cl: 0.95-0.98; 
Figure 5), and the results of the DOR forest map for heterogeneity testing were $P=0.00$, I-square= 99.35. A metaregression analysis was performed based on the study design (prospective or retrospective), year of publication, country of publication, sample size(number of patients enrolled being 21-100,100-200,囚200)囚patient ethnicity, application of $\mathrm{CRH}$ or DDAVP, and application of PRL correction (Figure 6). The results suggested that the research design was the main cause of heterogeneity. Deek's asymmetry test was used to detect the presence of publication bias, and the results indicated a publication bias $(P=0.01$; Figure 7$)$.

Table 1. Characteristics of the included studies 


\begin{tabular}{|c|c|c|c|c|c|c|c|c|c|c|}
\hline Author & Year & Country & Design & Stimulation & $\begin{array}{l}\text { PRL } \\
\text { adjust }\end{array}$ & $\begin{array}{l}\text { Gold } \\
\text { Standard }\end{array}$ & TP & FP & FN & $\mathrm{TN}$ \\
\hline $\begin{array}{l}\text { Oldfield } \\
\mathrm{EH}^{6}\end{array}$ & 1991 & USA & pro & $\mathrm{CRH}$ & No & Pathology & 203 & 0 & 0 & 17 \\
\hline $\begin{array}{l}\text { Findling } \\
\mathrm{JW}^{27}\end{array}$ & 1991 & USA & pro & $\mathrm{CRH}$ & No & Pathology & 18 & 3 & 2 & 6 \\
\hline $\begin{array}{l}\text { Kaltsas } \\
\mathrm{GA}^{28}\end{array}$ & 1999 & UK & retro & $\mathrm{CRH}$ & No & Pathology & 50 & 0 & 19 & 6 \\
\hline Invitti $C^{29}$ & 1999 & Italy & retro & DDAVP & No & Pathology & 65 & 0 & 11 & 9 \\
\hline $\begin{array}{l}\text { Bonelli } \\
\mathrm{FS}^{13}\end{array}$ & 2000 & USA & retro & $\mathrm{CRH}$ & No & Pathology & 71 & 1 & 6 & 9 \\
\hline $\begin{array}{l}\text { Wiggam } \\
\mathrm{Ml}^{30}\end{array}$ & 2000 & $\begin{array}{l}\text { Northen } \\
\text { Ireland }\end{array}$ & retro & $\mathrm{CRH}$ & No & Pathology & 36 & 0 & 8 & 1 \\
\hline Colao $A^{12}$ & 2001 & Italy & retro & $\mathrm{CRH}$ & No & Pathology & 60 & 0 & 8 & 10 \\
\hline $\begin{array}{l}\text { Lefournier } \\
\mathrm{V}^{31}\end{array}$ & 2003 & France & retro & $\mathrm{CRH}$ & No & Pathology & 65 & 2 & 4 & 6 \\
\hline $\begin{array}{l}\text { Swearingen } \\
\mathrm{B}^{32}\end{array}$ & 2004 & USA & retro & $\mathrm{CRH}$ & Yes & Pathology & 70 & 2 & 9 & 2 \\
\hline Liu $C^{33}$ & 2004 & USA & retro & $\mathrm{CRH}$ & No & Pathology & 39 & 0 & 3 & 9 \\
\hline $\begin{array}{l}\text { Kaskarelis } \\
\mathrm{LS}^{3}\end{array}$ & 2006 & Greece & retro & $\mathrm{CRH}$ & No & Pathology & 40 & 3 & 6 & 5 \\
\hline $\begin{array}{l}\text { Machado } \\
\text { MC }^{34}\end{array}$ & 2006 & Brazil & retro & $\mathrm{CRH}$ & No & Pathology & 46 & 0 & 1 & 5 \\
\hline $\begin{array}{l}\text { Castinetti } \\
\mathrm{F}^{35}\end{array}$ & 2007 & France & retro & DDAVP & Yes & Pathology & 32 & 0 & 4 & 7 \\
\hline $\begin{array}{l}\text { Tsagarakis } \\
S^{36}\end{array}$ & 2007 & Greece & retro & $\mathrm{CRH}$ & No & Pathology & 46 & 0 & 1 & 7 \\
\hline Shi $X H^{37}$ & 2011 & China & retro & No & No & Pathology & 58 & 1 & 10 & 4 \\
\hline $\begin{array}{l}\text { Mulligan } \\
\text { GB }^{38}\end{array}$ & 2011 & USA & retro & $\mathrm{CRH}$ & No & Pathology & 33 & 1 & 2 & 1 \\
\hline $\begin{array}{l}\text { Andereggen } \\
L^{39}\end{array}$ & 2011 & Switzerland & retro & $\mathrm{CRH}$ & No & Pathology & 19 & 1 & 1 & 2 \\
\hline $\begin{array}{l}\text { Sharma } \\
\mathrm{ST}^{40}\end{array}$ & 2011 & USA & retro & No & No & Pathology & 16 & 1 & 1 & 7 \\
\hline $\begin{array}{l}\text { Shetch } \\
S A^{41}\end{array}$ & 2012 & USA & retro & $\mathrm{CRH}$ & Yes & Pathology & 195 & 5 & 12 & 5 \\
\hline Grant $\mathrm{P}^{42}$ & 2012 & UK & retro & $\begin{array}{l}\text { DDAVP } \\
\text { Page 6/19 }\end{array}$ & No & Pathology & 72 & 1 & 0 & 10 \\
\hline
\end{tabular}




\begin{tabular}{|c|c|c|c|c|c|c|c|c|c|c|}
\hline Zhou WW ${ }^{43}$ & 2016 & China & pro & No & No & Pathology & 84 & 1 & 3 & 5 \\
\hline $\begin{array}{l}\text { Jarial } \\
\text { KDS }^{44}\end{array}$ & 2018 & India & pro & $\mathrm{CRH}$ & No & Pathology & 26 & 0 & 0 & 2 \\
\hline $\begin{array}{l}\text { Pereria } \\
\mathrm{CA}^{45}\end{array}$ & 2019 & Portugal & retro & No & No & Pathology & 27 & 0 & 1 & 2 \\
\hline
\end{tabular}

\section{Discussion}

This study was the first meta-analysis to evaluate the differential diagnostic value of BIPSS in ACTH-dependent Cushing syndrome. It included a total of 23 studies and 1,617 patients. Our results suggested that the sensitivity and specificity of BIPSS to pituitary or ectopic ACTH were $94 \%$ and $89 \%$, respectively, indicating that BIPSS has high value in the differential diagnosis of ACTH-dependent Cushing syndrome. In addition, the DOR value was also high, suggesting that BIPSS could effectively identify the ACTH source. The area under the SROC curve was 0.97 , suggesting that the overall diagnostic performance of BIPSS was effective.

BIPSS has a high value in the differential diagnosis of CS cases that have typical CS presentations clinically and biochemically but have an unclear ACTH source. Because BIPSS does not identify the ACTH source from a morphological perspective, but from a functional perspective, this diagnostic approach is accurate, with relatively high sensitivity and specificity. CD accounts for a large proportion of ACTH-dependent Cushing syndrome cases, and BIPSS is particularly suitable for patients with negative MRI results. Furthermore, BIPSS provides an important basis for guiding the surgical treatment of this disease.

In most cases, the ACTH level of CD was lower than EAS. For example, the ACTH level of the ACTH-secreting tumors was $111.35 \mathrm{pg} / \mathrm{ml}$, while the ACTH level of EAS was $277.01 \mathrm{pg} / \mathrm{ml}$ [37]. After CRH or DDAVP stimulation, the ACTH level increased significantly. Many researchers believe that the stimulation intensity of DDVAP on ACTHsecreting tumors is weaker than that of CRH. For example, in Jarial's study, the ACTH (IPS/P) ratio of ACTHsecreting tumors is increased 11.6-fold after DDAVP stimulation. After CRH stimulation, the ratio is increased by 28-fold [44]. In terms of the maximum ACTH level after stimulation, Bonelli's study showed that the ACTH levels reached $1,062 \mathrm{pg} / \mathrm{ml}$ after DDAVP stimulation, and $3,058 \mathrm{pg} / \mathrm{ml}$ after CRH stimulation [13]. This leads naturally to the question of why the stimulation intensity of DDAVP is weaker than that of $\mathrm{CRH}$. We believe that $\mathrm{CRH}$ directly stimulates ACTH, and stimulation of DDVAP is due to the presence of vasopressin receptor. Thus, the stimulation intensity of DDVAP is weaker than that of CRH.

BIPSS has a high differential diagnostic value for CD and EAS. Application of CRH or DDVAP stimulation enhances the sensitivity and specificity of BIPSS. However, BIPSS should still be combined with other diagnostic methods, such as imaging, HDDST, and the low-dose dexamethasone suppression test for comprehensive diagnosis.

False negative results can occur in BIPSS. These have been reported to be approximately $10 \%$ [32], and may be related to operational failure or abnormal venous drainage from the inferior petrosal sinus. BIPSS is not ideal for identifying the diseased side $[31,46]$, which may be due to the presence of branches joined to the cavernous sinus and frequent contralateral venous return. A previous study used cavernous sinus sampling instead of BIPSS to obtain a good differential diagnosis for CD and EAS [47]. For BIPSS, the success rate is closely related to the 
operator's technique and experience, and accurate catheterization is very important. Results of a previous study suggest that PRL for correction improves the success rate of catheterization [48].

An interesting consideration is whether the false positive rate of BIPSS increases among the patients with positive MRI results, which is only discussed in few studies. The study by Kaskarelis et al. showed that 1 out of $23 \mathrm{MRI}$ positive patients had a BIPSS-false-negative result (4.3\%) and 2 out of 55 MRI-negative patients had BIPSS-falsenegative results (3.6\%) [3], while the majority of BIPSS-false-positive rates in CS patients ranged from 0 to $5 \%$. Thus, the BIPSS-false-positive rate of the MRI-positive patients in Kaskarelis et al.'s study was higher than that of the MRI-negative patients, and also higher than the average of most other studies. Maybe after being stimulated, the MRI positive patients still secreted a little more ACTH. Since few studies were related to this issue, further studies with increased sample sizes are needed for verification.

This meta-analysis provides implications for future studies as follows: PRL can be used as a reference to improve the accuracy of catheterization during BIPSS. CRH or DDAVP stimulation should also be used during BIPSS to improve the sensitivity and specificity.

The strengths of this study were that we followed a standard protocol and used a comprehensive search strategy. Furthermore, the bivariate random effects model and hierarchical summary ROC analyses were used. Finally, meta-regression analysis suggested that the source of heterogeneity was mainly in the experimental design.

However, our meta-analysis also had some limitations. First, some details of patient characteristics were not available, which might affect our appraisal of the diagnostic value of BIPSS. Second, the analysis used summarized data, which restricted us from conducting more detailed analysis. Finally, the publication bias of this meta-analysis was $\mathrm{P}<0.05$, suggesting the presence of publication bias. The possible reasons for this were that (1) BIPSS had high diagnostic accuracy of TP and TN for determining the ACTH source and likely shows the ideal statistical results in the software, leading to the calculation of publication bias; (2) authors might have submitted studies only with positive results to increase the chance of being published; and (3) this meta-analysis only included studies published in Chinese and English.

This study was the first meta-analysis to evaluate BIPSS's effects on determining the etiology of ACTH-dependent Cushing syndrome, suggesting that BIPSS had a great differential diagnostic value for the ACTH source. Results of this study require further large-scale prospective studies to validate the differential diagnostic value of BIPSS for ACTH-secretion sources in different patients.

\section{Conclusion:}

This meta-analysis indicated that BIPSS had a high diagnostic value for patients with ACTH-dependent Cushing syndrome, and as such, BIPSS should be used as a routine method to identify ACTH-secretion sources. CRH or DDAVP stimulation should be used during BIPSS to improve the test's sensitivity and specificity.

\section{Declarations}

\section{Ethics approval and consent to participate}

Not applicable. 


\section{Consent for publication}

Not applicable

\section{Availability of data and materials}

Not applicable. This study is a systematic review and we used primary data, which are already publicly available.

\section{Competing interests}

The authors declare that they have no competing interests.

\section{Funding}

This research received no specific grant from any funding agency in the public, commercial, or not-for-profit sectors.

\section{Authors' contributions}

$H W, Y B$ conceived and designed the study and approved the final draft of the manuscript submitted for review and publication; YB, QX and RCC searched databases, data extracted and study selection. HW performed data analysis. HW,YB,QX,RCC wrote the manuscript. All authors read and approved the final manuscript.

\section{Acknowledgements}

The authors would like to acknowledge all authors of the original studies that were included in this meta-analysis.

\section{References}

1. Ezzat S, Asa SL, Couldwell WT, Barr CE, Dodge WE, Vance ML, et al. The prevalence of pituitary adenomas: a systematic review. Cancer. 2004 Aug 1;101(3):613-619.

2. Guignat L, Bertherat J. The diagnosis of Cushing's syndrome: an Endocrine Society Clinical Practice Guideline: commentary from a European perspective. Eur J Endocrinol.2010 Jul;163(1):9-13. doi: 10.1530/EJE-09-0627. Epub 2010 Apr 7.

3. Kaskarelis IS, Tsatalou EG, Benakis SV, Malagari K, Komninos I, Vassiliadi D, et al. Bilateral inferior petrosal sinuses sampling in the routine investigation of Cushing's syndrome: a comparison with MRI. AJR Am J Roentgenol. 2006 Aug;187(2):562-570.

4. Doppman JL, Frank JA, Dwyer AJ, Oldfield EH, Miller DL, Nieman LK, et al.Gadolinium DTPA enhanced MR imaging of ACTH-secreting microadenomas of the pituitary gland. J Comput Assist Tomogr. 1988 SepOct;12(5):728-735.

5. Tabarin A,Laurent F, Catargi B, Olivier-Puel F, Lescene R, Berge J, et al. Comparative evaluation of conventional and dynamic magnetic resonance imaging of the pituitary gland for the diagnosis of Cushing's disease. Clin Endocrinol (Oxf). 1998 Sep;49(3):293-300. 
6. Oldfield EH, Doppman JL, Nieman LK, Chrousos GP, Miller DL, Katz DA, et al. Petrosal sinus sampling with and without corticotrophin-releasing hormone for the differential diagnosis of Cushing's syndrome. N Eng $\mathrm{J}$ Med 1991;325:897-905

7. Grossman AB, Kelly P, Rockall A, Bhattacharya S, McNicol A, Barwick T. Cushing's syndrome caused by an occult source: difficulties in diagnosis and management. Nat Clin Pract Endocrinol Metab. 2006 Nov; 2(11):642-647.

8. Howlett TA, Drury PL, Perry L, Doniach I, Rees LH, Besser GM. Diagnosis and Management of ACTHdependent Cushing's Syndrome: Comparison of the Features in Ectopic and Pituitary ACTH Production. Clin Endocrinol (Oxf) . 1986 Jun;24(6):699-713

9. D C Aron , H Raff, J W Findling Effectiveness Versus Efficacy: The Limited Value in Clinical Practice of High Dose Dexamethasone Suppression Testing in the Differential Diagnosis of Adrenocorticotropin-Dependent Cushing's Syndrome J Clin Endocrinol Metab . 1997 Jun;82(6):1780-5

10. Barbot M, Trementino L, Zilio M, Ceccato F, Albiger N, Daniele A, et al. Second-line Tests in the Differential Diagnosis of ACTH-dependent Cushing's Syndrome. Pituitary . 2016 Oct;19(5):488-95

11. T B Kaye , L Crapo. The Cushing Syndrome: An Update on Diagnostic Tests. Ann Intern Med . 1990 Mar 15;112(6):434-44

12. Colao A, Faggiano A, Pivonello R, Pecori Giraldi F, Cavagnini F, Lombardi G et al. Inferior petrosal sinus sampling in the differential diagnosis of Cushing's syndrome: results of an Italian multicenter study. Eur $\mathrm{J}$ Endocrinol. 2001 May;144(5):499-507

13. Bonelli FS, Huston J, Carpenter PC, Erickson D, Young WF Jr, Meyer FB. Adrenocorticotropic hormonedependent Cushing's syndrome: sensitivity and specifcity of inferior petrosal sinus sampling. American Journal of Neuroradiology 2000; 21: 690-696

14. Dahia PL, Ahmed-Shuaib A, Jacobs RA,Chew SL, Honegger J, Fahlbusch R, et al. Vasopressin receptor expression and mutation analysis in corticotropin-secreting tumors. J Clin Endocrinol Metab. 1996 May; 81(5):1768-1771.

15. Castinetti F, Morange I, Dufour H, Jaquet P, Conte-Devolx B, Girard N, et al. Desmopressin test during petrosal sinus sampling: a valuable tool to discriminate pituitary or ectopic ACTH-dependent Cushing's syndrome Eur J Endocrinol. 2007 Sep;157(3):271-277.

16. Gandhi CD, Meyer SA, Patel AB, Johnson DM, Post KD. Neurologic complications of inferior petrosal sinus sampling. AJNR Am J Neuroradiol. 2008 Apr; 29(4):760-765.

17. Tabarin A, Greselle JF, San-Galli F, Leprat F, Caille JM, Latapie JL, et al. Usefulness of the corticotropinreleasing hormone test during bilateral inferior petrosal sinus sampling for the diagnosis of Cushing's disease. .

18. Leeflang MM, Deeks JJ, Gatsonis C, Bossuyt PM; Cochrane Diagnostic Test Accuracy Working Group. System reviews of diagnostic test accuracy. Ann Intern Med. 2008 Dec 16;149(12):889-897.

19. Whiting P, Rutjes AW, Reitsma JB, Bossuyt PM, Kleijnen J. The development of QUADAS: a tool for the quality assessment of studies of diagnostic accuracy included in systematic reviews. BMC Med Res Methodol 2003 Nov 10;3:25.

20. Whitign PF, Weswood ME, Rutjes AW, Reitsma JB, Bossuyt PN, Kleijnen J. Evaluation of QUADAS, a tool for the quality assessment of diagnostic accuracy studies. BMC Med Methodol. 2006 Mar 6;6;9

Page 10/19 
21. Reitsma JB, Glas AS, Rutjes AW, Scholten RJ, Bossuyt PM, Zwinderman AH. Bivariate analysis of sensitivity and specificity produces informative summary measures in diagnostic reviews J Clin Epidemiol. 2005 Oct;58(10):982-990

22. Walter SD. Properties of the summary receiver operating characteristic (SROC) curve for diagnostic test data. Stat Med 2002; 9:1237-1256.

23. Deeks JJ, Higgins JPT, Altman DG. Analyzing data and undertaking meta-analyses. In: Higgins J, Green S, eds. Cochrane Handbook for Systematic Reviews of Interventions 5.0.1. Oxford, UK: The Cochrane Collaboration: 2008; chap 9.

24. Higgins JP, Thompson SG, Deeks JJ, Altman DG. Measuring inconsistency in meta- analyses. BMJ 2003; 327: $557-560$

25. Altman DG , Bland JM . Interaction revisited: the difference between two estimates. BMJ . 2003 Jan 25;326(7382):219.

26. Deeks JJ, Macaskill P, Irwig L. The performance of tests of publication bias and other sample size effects in systematic reviews of diagnostic test accuracy was assessed. J Clin Epidemiol 2005; 58: 882-893.

27. Findling JW, Kehoe ME, Shaker JL, Raff H. Routine inferior petrosal sinus sampling in the differential diagnosis of adrenocorticotropin(ACTH) dependent Cushing;s syndrome: early recognition of the occult ectopic ACTH syndrome. J Clin Endocrinol Metab. 1991 Aug; 73 (2) : 408-413.

28. Kaltsas GA, Giannulis MG, Newell -Price JD, Dacie JE, Thakkar C, Afshar F ,et al. A critical analysis of the value of simultaneous inferior petrosal sinus sampling in Cushing's disease and the occult ectopic adrenocorticotropin syndrome. J Clin Endocrinol Metab. 1999 Feb;84(2):487-92.

29. Invitti C, Pecori Giraldi F, de Martin M, Cavagnini F. Diagnosis and Management of Cushing's Syndrome: Results of an Italian Multicentre Study. J Clin Endocrinol Metab.1999 Feb;84(2):440-448.

30. Wiggam M, Heaney AP, Mcllrath EM, McCance DR, Sheridan B, Hadden DR, et al. Bilateral Inferior Petrosal Sinus Sampling in the Differential Diagnosis of Adrenocorticotropin -Dependent Cushing's Syndrome: A Comparison with Other Diagnostic Tests. J Clin Endocrinol Metab. 2000 Apr;85(4):1525-1532.

31. Lefournier V, Martinie M, Vasdev A, Bessou P, Passagia JG, Labat-Moleur F, et al. Accuracy of bilateral inferior petrosal or cavernous sinuses sampling in predicting the lateralization of Cushing's .disease pituitary microadenoma: influence of catheter position and anatomy of venous drainage. J Clin Endocrinol Metab. 2003 Jan;88(1):196-203.

32. Swearingen B, Katznelson L, Miller K, Grinspoon S, Waltman A, Dorer DJ, et al. Diagnostic errors after inferior petrosal sinus sampling. J Clin Endocrinol Metab. 2004 Aug; 89 (8) : 3752-3763

33. Liu C, Lo JC, Dowd CF, Wilson CB, Kunwar S, Aron DC, et al .Cavernous and inferior petrosal sinus sampling in the evaluation of ACTH-dependent Cushing's syndrome. Clin Endocrinol 2004 Oct;61(4): 478-486.

34. Machado MC, de Sa SV, Domenice S, Fragoso MC, Puglia P Jr, Pereira MA, et al. The role of desmopressin in bilateral and simultaneous inferior petrosal sinus sampling for differential diagnosis of ACTH-dependent Cushing's syndrome. Clin Endocrinol (Oxf). 2007 Jan;66(1):136-142.

35. Castinetti F, Morange I, Dufour H, Jaquet P, Conte-Devolx B, Girard N, et al. Desmopressin test during petrosal sinus sampling: a valuable tool to discriminate pituitary or ectopic ACTHdependent Cushing's syndrome. Eur J Endocrinol. 2007 Sep;157(3):271-277.

36. Tsagarakis S, Vassiliadi D, Kaskarelis IS, et al. The application of the combined corticotrophin-releasing hormone plus desmopressin stimulation during petrosal sinus sampling is both sensitive and specifc in 
differentiating patients with Cushing's disease from patients with the occult ectopic adrenocorticotropin syndrome. J Clin Endocrinol Metab.2007 Jun;92(6):2080-6. Epub 2007 Mar 13.

37. Shi X, Sun Q, Bian L, Zhao W, Shen J, Wang W, Ning G. Assessment of bilateral inferior petrosal sinus sampling in the diagnosis and surgical treatment of the ACTH-dependent Cushing's syndrome:a comparison with other tests. Neuro Endocrinol Lett $2011 ; 32: 865-873$.

38. Mulligan GB, Eray E, Faiman C, Gupta M, Pineyro MM, Makdissi A, et al. Reduction of false-negative results in inferior petrosal sinus sampling with simultaneous prolactin and corticotropin measurement. Endocrine Practice 2011; 17: 33-40.

39. Andereggen L, Schroth G, Gralla J, Seiler R, Mariani L, Beck J,et al. Selective inferior petrosal sinus sampling without venous outflow diversion in the detection of a pituitary adenoma in Cushing's syndrome. Neuroradiology 2012;54: 495-503.

40. Sharma ST, Raff H, Nieman LK. Prolactin as a marker of successful catheterization during IPSS in patients with ACTH-dependent Cushing's syndrome. J Clin Endocrinol Metab. 2011 Dec;96(12):3687-94.

41. Sheth SA, Mian MK, Neal J, Tritos NA, Nachtigall L, Klibanski A ,et al. Transphenoidal surgery for cushing disease after nondiagnostic inferior petrosal sinus Neurosurgery $2012 ; 71: 14-22$.

42. Grant P, Dworakowska D , Carroll P. Maximizing the accuracy of Inferior petrosal sinus sampling: validation of the use of Prolactin as a marker of pituitary venous effluent in the diagnosis of Cushing's disease. Clin Endocrinol 2012; 76: 555-559.

43. WW Zhou,TW Su,L Jiang,YR Jiang,H Zhang,ZY Wu,et al. The clinical application of adjusted inferior petrosal sinus sampling in Cushing's disease. Chin Endo Metab,2016 Mar;32,3:196-200.

44. Jarial KDS, Bhansali A, Gupta V, Singh P, Mukherjee KK, Sharma A, et al. Diagnostic accuracy and comparison of BIPSS in response to lysine vasopressin and hCRH. Endocr Connect. 2018 Mar;7(3):425-432.

45. Pereira CA, Ferreira L, Amaral C, Alves V, Xavier J, Ribeiro I, et al. Diagnostic accuracy of Bilateral Inferior Petrosal Sinus Sampling: The Experience of a Tertiary Centre. Exp Clin Endocrinol Diabetes. 2019 Aug 19. doi: 10.1055/a-0981-5973.

46. Chen S, Chen K, Lu L, Zhang X, Tong A, Pan H et al. The effects of sampling lateralization on bilateral inferior petrosal sinus sampling and desmopressin stimulation test for pediatric Cushing's disease. Endocrine. 2019 Mar;63(3):582-591.

47. L Hayashi N, Kurimoto M, Kubo M, Kuwayama N, Kurosaki K, Nagai S, et al. The impact of cavernous sinus drainage pattern on the results of venous sampling in patients with suspected cushing syndrome. AJNR Am J Neuroradiol. 2008 Jan;29(1):69-72. Epub 2007 Oct 9.

48. Findling JW, Kehoe ME, Raff H. Identification of patients with Cushing's disease with negative pituitary adrenocorticotropin gradients during inferior petrosal sinus sampling: prolactin as an index of pituitary venous effluent. J Clin Endocrinol Metab. 2004 Dec; 9 (12):6005-6009.

\section{Figures}




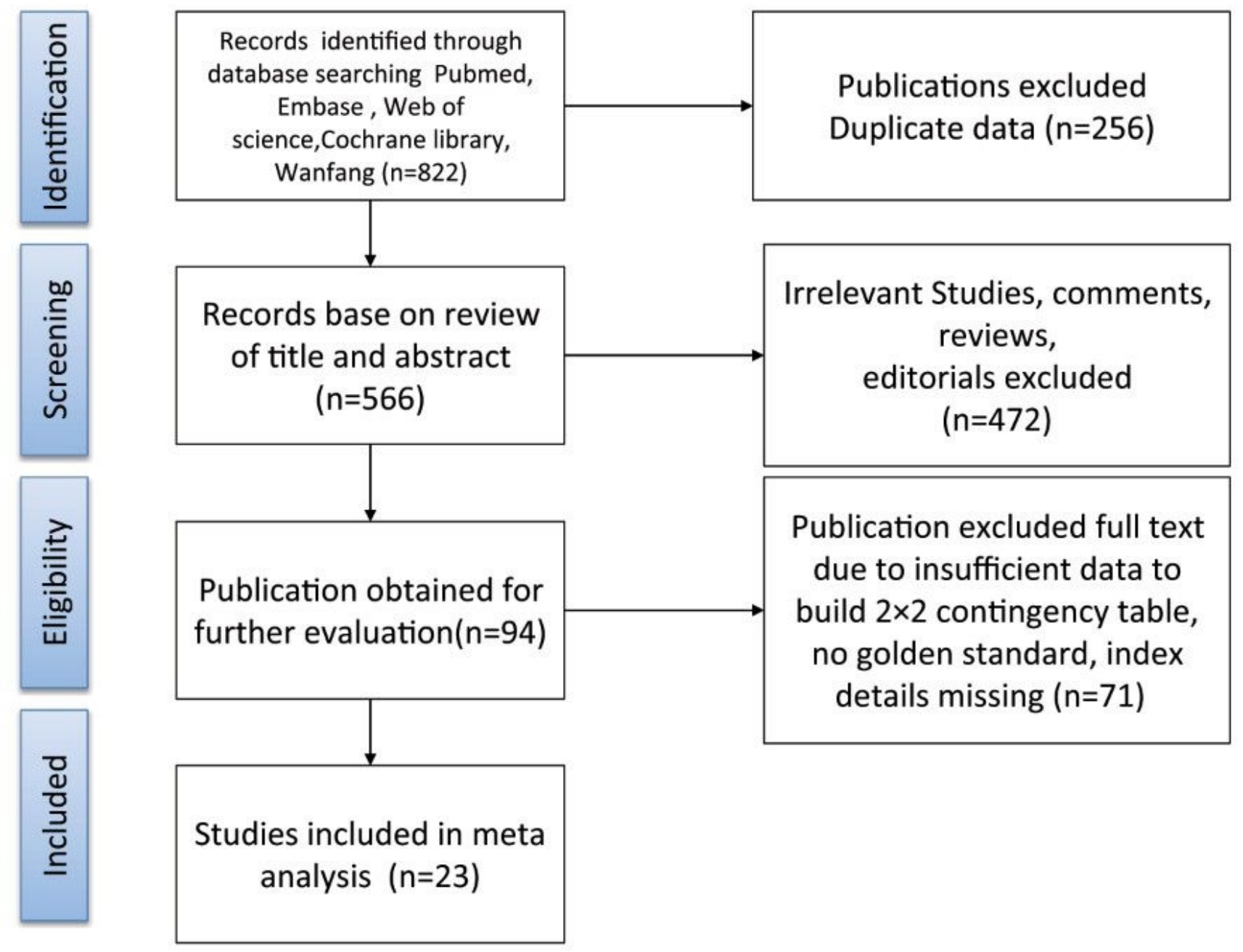

Figure 1

Retrieval flowchart to obtain study data for meta-analysis 


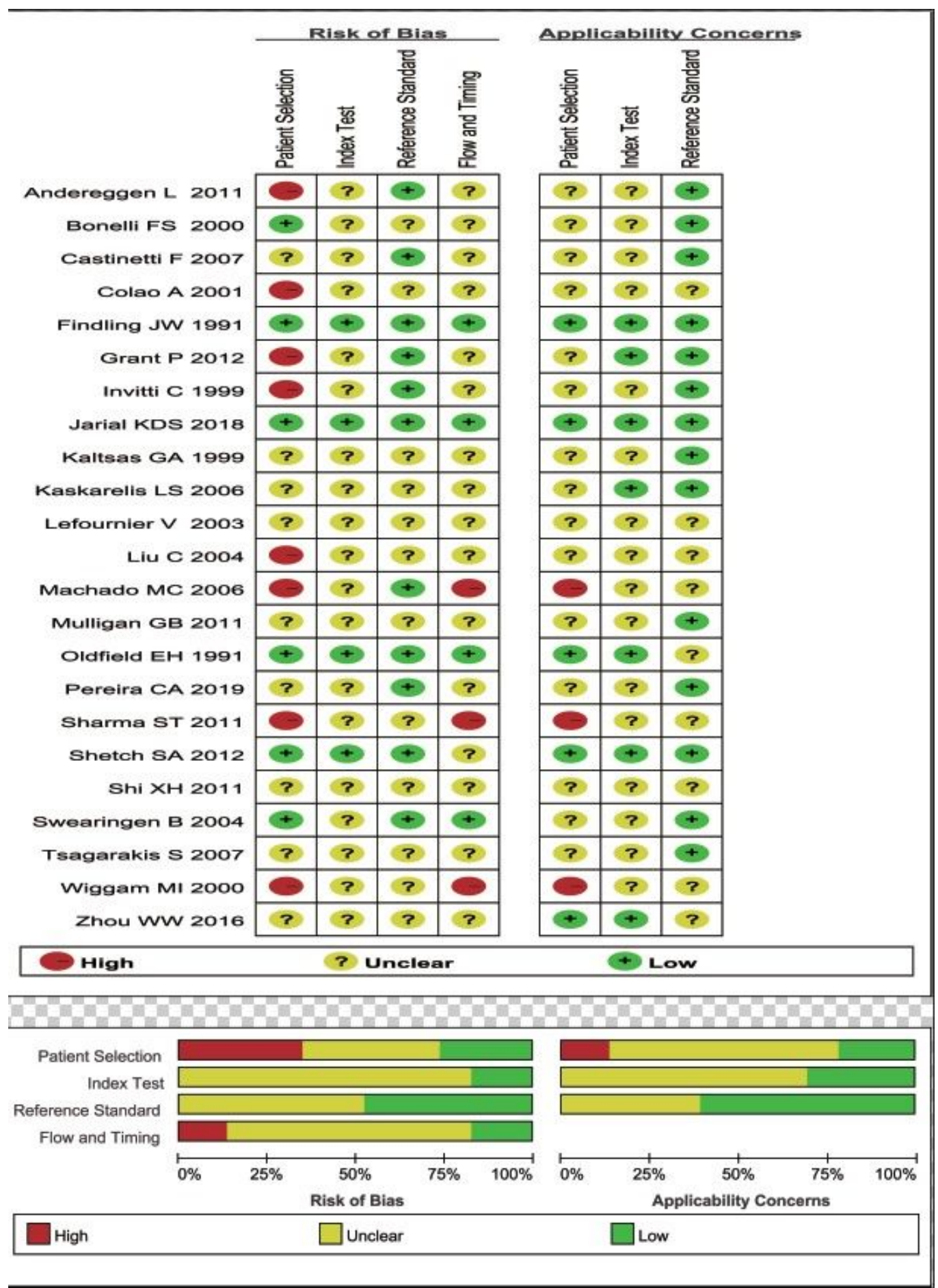

\section{Figure 2}

Quality assessments for the included studies 


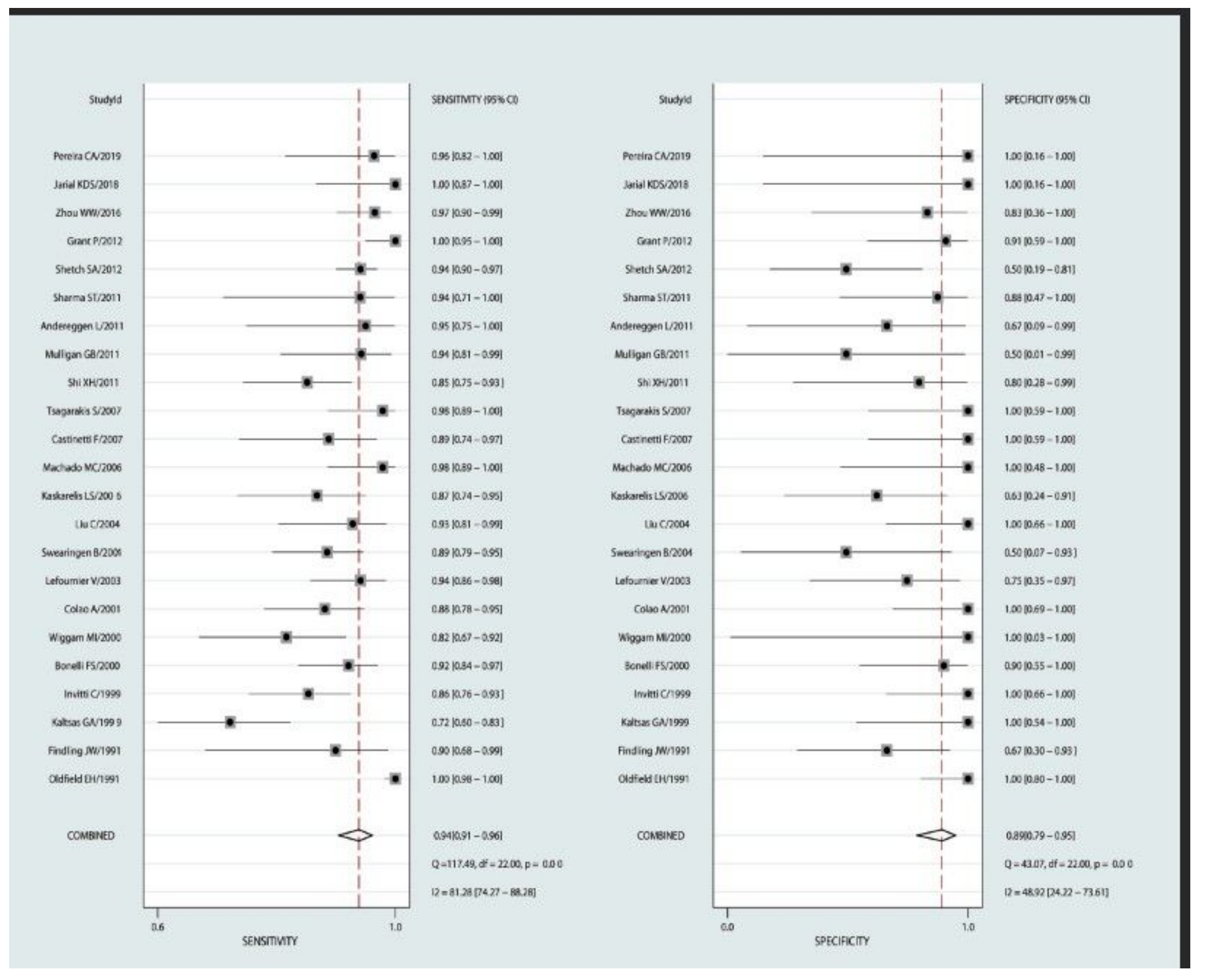

Figure 3

Forest plot for sensitivity and specificity 


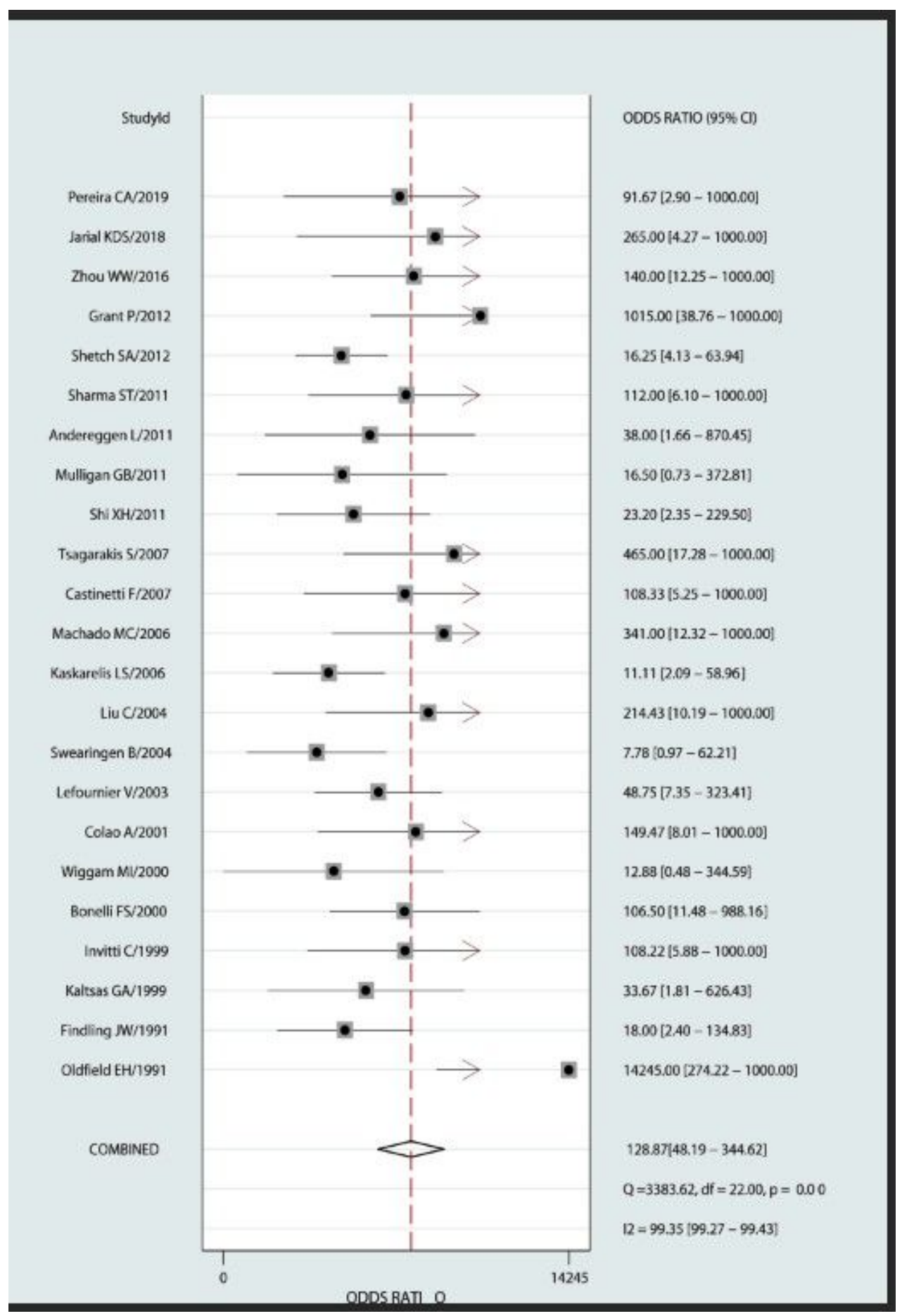

Figure 4

Forest plot for DOR 


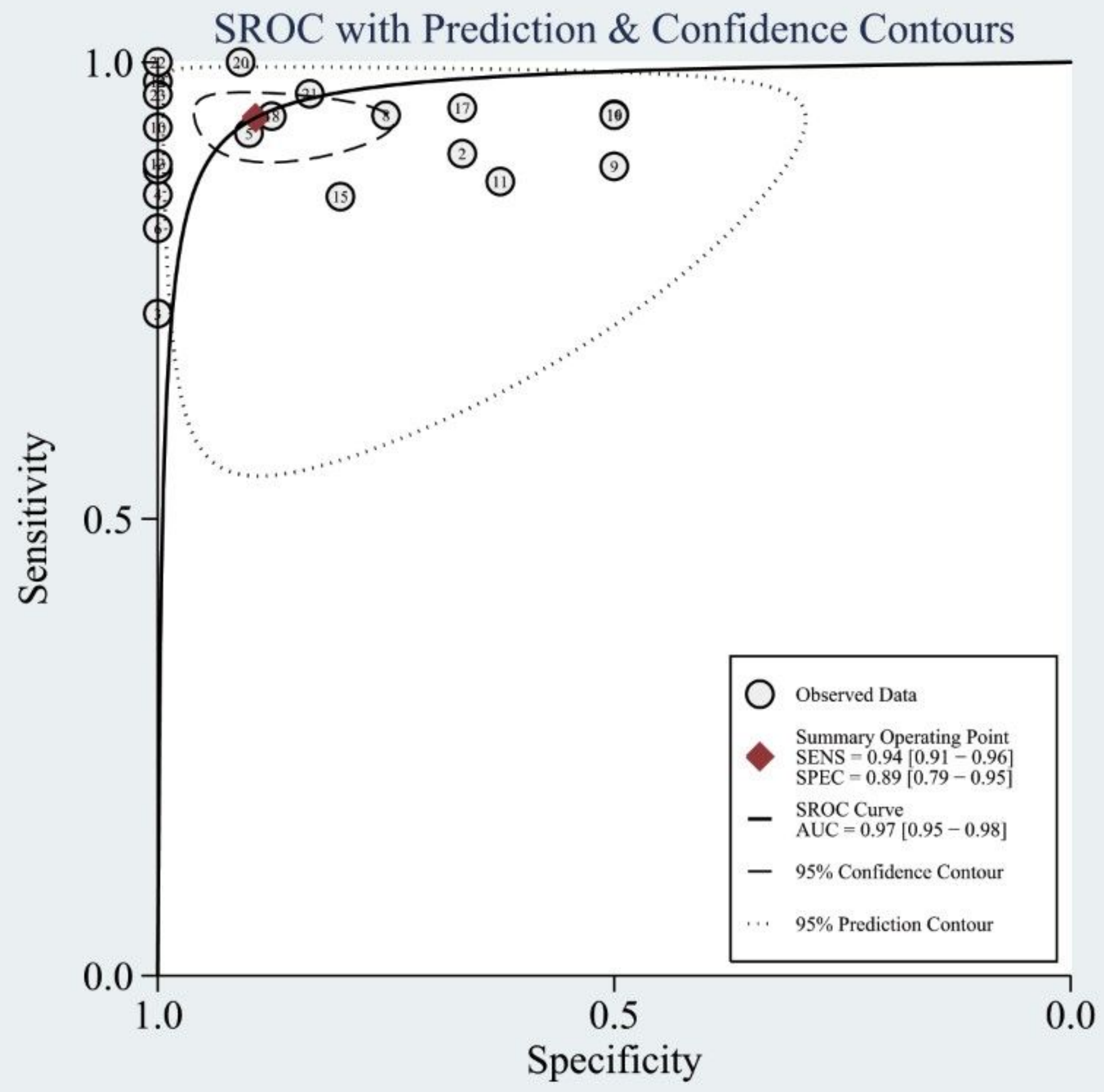

Figure 5

Area under the ROC curve 


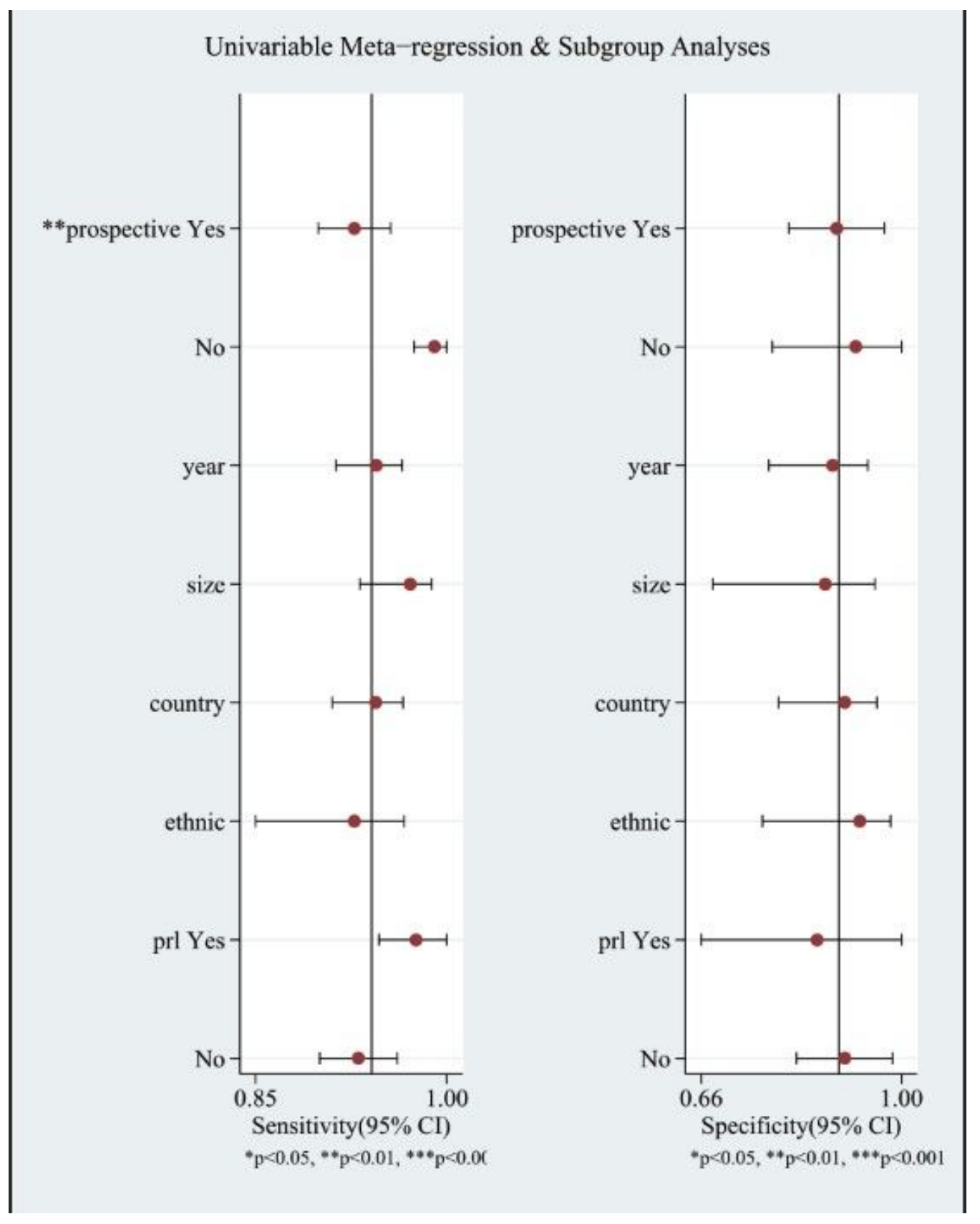

Figure 6

Meta-regression analysis for DOR 


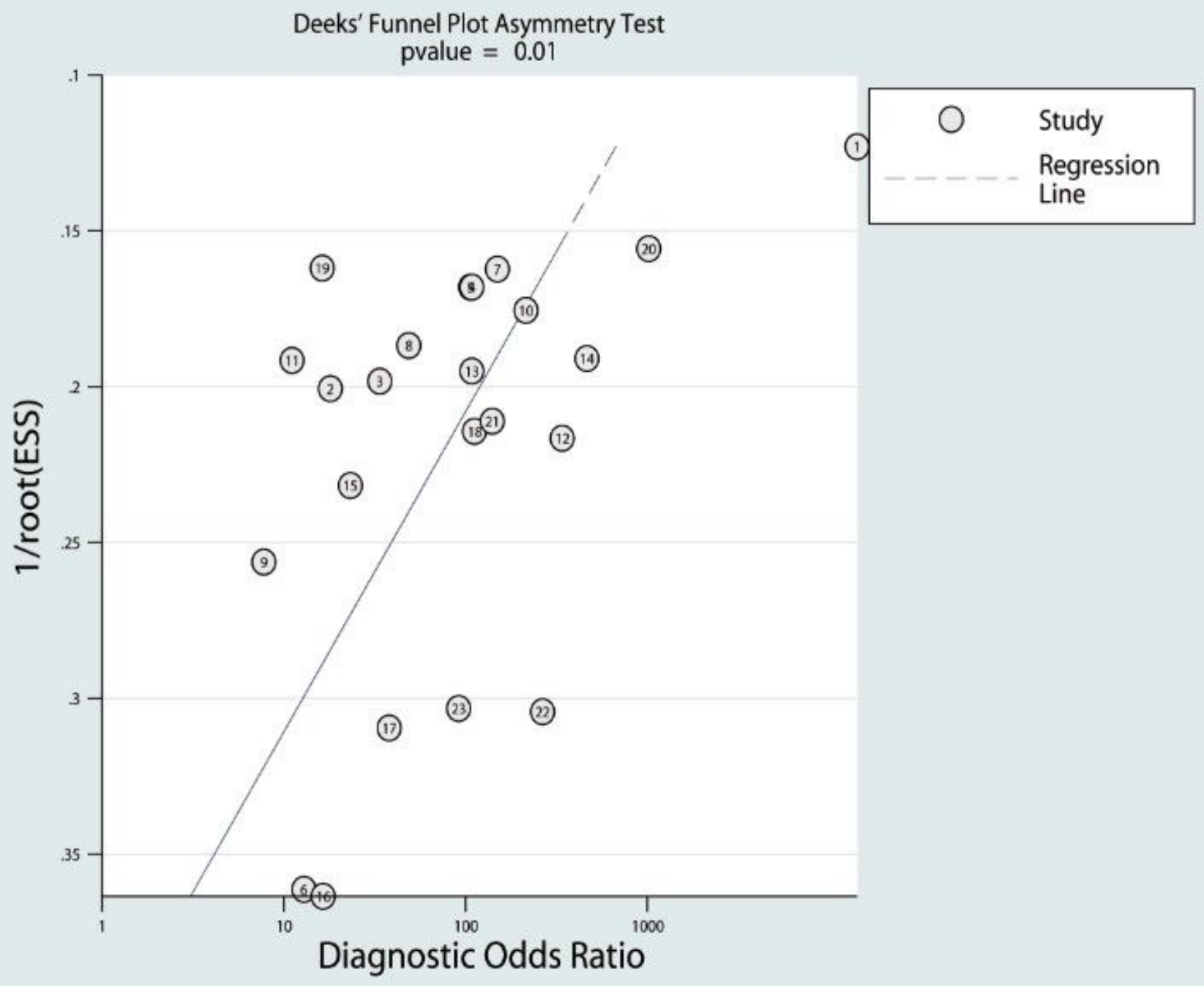

Figure 7

Deek's plot for BIPSS in the differential diagnosis of ACTH-dependent CS

\section{Supplementary Files}

This is a list of supplementary files associated with this preprint. Click to download.

- PRISMA2009Checklist2020.06.27.doc 